\title{
Synthesis and Novelty for Developing the Framework in Academic Writing
}

\author{
Djuwari, Djuwari \\ STIE Perbanas Surabaya, Indonesia
}

\begin{tabular}{l} 
Article history: \\
Submitted: 28 March 2021 \\
Revised: 16 May 2021 \\
Accepted: 15 June 2021 \\
\hline Keywords: \\
Language \\
Syntheses \\
Novelty \\
Coherence \\
Cohesion \\
Academic writing framework
\end{tabular}

product of academic writing - the authors write will be eligible for publication.

ABSTRACT. In academic writing, the authors have to cite other references as the basis of the arguments they have to assert. This citation is important in academic writing. However, writing all the statements in a research paper or article needs analyzing and synthesizing. From this activity, the authors can develop the frameworks for creating the novelty. This article attempts to explain how to quote the statements based on the references and build the framework by synthesizing and creating the novelty. First, the texts cited are rearranged and analyzed using the concept of cohesiveness and coherence. They are presented in tables to see the differences and similarities. Then, they are synthesized. Thus, all references cited are finally ended with the refined arguments as the new ideas as the novelty of the research paper. It can be inferred that by using the concept of cohesiveness and coherence, the authors of academic writing can synthesize all the citations and create novelty. The authors should create novelty by synthesizing all the references they have already cited. By doing so, the research paper-as the

\subsection{Introduction}

In academic writing, the authors need to understand how to quote and cite the names of the authors based on their standpoints of view. From these different points of view, the authors should identify both the similarities and differences. For example, when dealing with the similarities, the authors should analyze them and judge those similarities (Knight et al., 2018). Similarly, when dealing with the differences among the quoted references, the authors should also provide a new idea based on the arguments in the different perspectives they have already cited (Patriotta, 2017).

Some previous studies have been conducted in academic writing on the students of colleges. For example, Abas and Abd Aziz (2017) conducted research related to the dissertation writing process and writing strategies. Students in colleges are required to write their research articles in the form of theses or dissertations. Besides that, Ahmed (2010) also studied the students' problems with cohesion and coherence in EFL essay writing. Being coherent is a must for writing the ideas in a thesis or dissertation. Another study was also done by Ahmad et al. (2019) on the analysis of synthesis writing. From some of these studies, it can be generalized that the authors should have knowledge and skill of synthesizing and creating novelty in academic writing. This effort also requires knowledge of skill in coherence and cohesion.

In the case above, analyzing the arguments, the authors have cited can produce a synthesis. This synthesis should be rewritten with the process of editing, revising, and finishing. In this process, the author should also include some important factors as practiced in academic writing. They are coherence, cohesion, and lexical resources. All these should be part of the assessment process in the whole writing process (Bacon \& Bounty, 2020). Synthesis is important in academic writing. Therefore, any piece of academic writing should show the process of synthesizing based on the references the author has cited. From these citations, the author should evaluate and then create his idea for building the framework.

This study was motivated by the fact that some authors in some published journals do not always interpret and analyze the sentences they have cited. This leads to poor analysis of the concepts the authors have read from the reference (Patriota, 2017). Therefore, the texts written are left as original ideas but not interpreted and analyzed. This could also be found in the research by Arufatul and Budinan (2017). Even the graduate students found it difficult to organize, interpret, and evaluate the texts. They also said that the authors need to claim their own ideas after reading and citing the sentences from the references.

Coherence and cohesiveness are important factors in academic writing for research journal publication. These two concepts can provide us with skills of incorporating the sentences so that there is an interrelationship of ideas among the sentences in the paragraphs or the texts. From these 
two concepts, when applied in academic writing, the authors can judge or evaluate and interpret the ideas that have been incorporated. Thus, the sentences that have been cited are synthesized. In general, the journal article authors need to make all statements or arguments - from the references they have cited-coherent and cohesive. In the end, the authors can judge and interpret for synthesizing the ideas they have grasped from all the arguments they have cited.

When the editors and reviewers of the research journals have the same perspectives on the importance of academic writing, they can also be the source persons to provide information to the authors for the guidelines using the academic writing for journal publication. In the end, the prospective authors can also get the knowledge given by the editors and reviewers about it. According to Patriota (2017), the journal publisher can also have a training program on these matters for the prospective authors. Thus, the result of this study is reallybeneficial for providing the readers who want to publish their articles in research journals.

\subsection{Framework of the Study}

Writing needs a systematic process so that the result or the writing product can be understood easily and efficiently. Concerning academic writing, such a process is required. Therefore, any author should be knowledgeable with coherence, cohesion, synthesis, novelty, and how to build the framework based on the references he has already cited (Ahmed, 2010; Irvin, 2010; and Alotaibi, 2015 ) that in academic writing, coherence and cohesiveness are important. Besides that, having all the sentences coherent and cohesive in the text, the authors can grasp the ideas and then interpret and evaluate for synthesizing (Moore, 2018; Mahoney et al. 2019; Djuwari, 2012; McCombes, 2020). By doing this all the time when writing, the authors can create novelty (Davis, 2011; McCombes, 2020; Trapido, 2015; and Shibayama\& Wang, 2020).

First, it is coherence. Coherence is vital in academic writing because it can show the author's way of constructing and relating all ideas he writes in one idea. In addition, coherence, or texture, combines semantic configurations of two different kinds: register and cohesion (Ahmed, 2010). In a further writing process, coherence can be attained by a certain way of putting ideas into writing. For example, whenever the author moves from one main point (primary support) to the next, the author needs to clearly signal the reader that this movement is happening. This transition sentence works best when it links back to the thesis as it states the topic of that paragraph or section (Irvin, 2010). Therefore, coherence in academic writing involves the authors' way of thinking about how to relate his ideas, with the process of moving from one main point to the next.

Another concept is cohesion. To be able to create coherence in writing, the author also needs to know about cohesion. When discussing the term cohesion, it deals with writing ideas in which the author should stress on the text. Then he also should determine the meaning that exists within the text. In addition, cohesion is considered important in academic writing because it stresses the text and the relationship between the elements in the text (Alotaibi, 2015). Thus, ideas in the sentences are interrelated and combined into a good way to become a united idea. Another proponent, Halliday and Hasan, in Alotaibi (2015), asserted that cohesion in the text is determined by the relations of meaning that exist within the text and that define it as a text. Thus, a text itself consists of sentencescontaining ideas - which should be interrelated and finally combined to create one idea as a whole.

When the writers have acquired the skills of making the texts coherent and cohesive, they will grasp the ideas of what they have written based on the references they have cited. Therefore, they have to synthesize the text. The concept of synthesis is also essential. Synthesis is defined in various ways. First, synthesis is the effort of describing the combination of two or more ideas or concepts into your writing using your own words (Moore, 2018). From this concept, the writer's synthesis in writing is done in which he describes it again with his own words by still basing on the resources or references he has already read. The references consist of different ideas, and then the writer should combine them into one new idea. Second, a synthesis involves combining two or more summaries; it must be done meaningfully. The final essay must generally be thesis-driven (Mahoney et al., 2019). It means that combining the sentences in a meaningful way (Djuwari, 2012). All sentences should be interrelated and must be created to become a new idea that is the author's own idea based on the combination of different sentences or ideas.

In a more detailed, synthesizing covers not only combining ideas from different sources but also leading the readers to be able to map the written text. First of all, synthesizing is indeed combining different aspects of your ideas and others in order to produce new ideas (McCombes, 2020). From 
this perspective, the author tries to evaluate all ideas he has already put into his paper into a new one-the synthesized one. This is the product of evaluating the ideas the author has read and written. Secondly, synthesizing also deals with the activity of mapping. For example, when students read, they have to map the ideas found in the text they read. In other words, the text catered for the students allows them to build new and meaningful knowledge, which is linked by active engagement (Davies, 2011). This process of mapping that can also be applied by the readers of the research writing products. Figure 1 shows the process of synthesizing.

\section{Research + More Research + Your Ideas $=$ Your New Ideas}

Figure 1. Process of Synthesizing (Davis, 2011)

There are four steps to synthesize in writing. In this case, McCombes (2020) provides us with four steps. They are as follows: 1) Organize the Sources; 2) Outline the Structure; 3) Write Paragraphs with Topic Sentences; 4) Revise, Edit, and Proofread. By applying these four steps, any writing product will be well-written because the sentences with the ideas are evaluated and interpreted. After that, they are edited and then revised. In the end, the result of this process creates a well-organized text and a synthesized idea.

The most vital at the end of writing the research article is creating the novelty. In academic writing, novelty is salient because it is considered the authors' original idea and a new product of knowledge that identifies the authors' high value of his writing. As elaborated, the term novelty is a production of new knowledge, and it is from the divergence of several sources (Trapido, 2015). Since it is a production of new knowledge, it is original. The author's process of analyzing the divergent ideas he has already read and cited has resulted from the author's process of analyzing the divergent ideas he has already read and cited. Besides that, novelty can also be developed by the author. The views originality is an innate feature of a scientific paper that can be measured at the event of publication, irrespective of the succeeding use of the paper (Shibayama\& Wang, 2020). Novelty shows the quality of the author's writing. It is also the originality of the writing made by the author. Thus, novelty is important because it can also show the author's view. It is originally based on his analysis and synthesis of different views he has already combined.

Based on the concept of coherence, cohesion, synthesis, and novelty, the author can create a whole summary of the originality of ideas. It is the framework developed from synthesizing, creating novelty by unitizing the author's knowledge and skill in making all interrelated ideas coherent that is supported by cohesion: the linguistic devices for connecting ideas in the wiring. In this case, the theoretical framework is another term that exists in any research writing. The author's framework has been built from various observations, materials or references, evidence, and library research.

\subsection{Methods}

Library research includes the step-by-step method to collect information to write a paper, create a presentation, or complete a project (Rasmuson, 2020). It can be done by getting references, analyzing, and synthesizing. In this study, the texts are basically from the relevant published researched journal articles.

The criteria for selecting the text are taken from the published journal articles by assuming that they had undergone a rigorous review. Otherwise, they were not published. From these texts, the researcher cited the sentences then analyzed and synthesized them. Thus, the texts are elaborated by the researcher in the process of making them coherent, cohesive. Then finally, the researcher synthesized them (see the process in Figure 1 and Figure 2). These articles are considered to have undergone rigorous review and therefore have been selected for publication. These are taken as examples for analysis and discussion. Some are modified by the researcher for making it proper for the discussion in relation to coherence, cohesion, and synthesis.

Based on selection criteria, the texts are cited (only those related to ideas for analysis and synthesis) from the published research journals. They are cited, analyzed using coherence and cohesion theories, and then synthesized (See Figure 1 and Figure 2). Therefore, the process of analysis is based on the concept of coherence, cohesiveness, and synthesis. This was done as proposed by 
Ahmed (2010), Irvin (2010), Clarke and Brown (2018), and Alotaibi (2015) for creating coherence and cohesiveness in the text. Then, the texts are synthesized as proposed by Davis (2011), Mahony, Macfarlane, and Ajjabi (2019) and McComber, (2020) for synthesizing process. From this process, the final mapping is the novelty (see Figure 4) is analyzed using the concepts of coherence and cohesion. The primary purpose of this analysis is to discover themes, topics, or situations that occur in the conversations or writings (Akinyode\& Khan, 2018). In addition, the researcher used, among others, the text analysis and inductive analysis method to understand the concept of the data. Then, the researcher summarizes the data of the texts (Clarke\& Braun, 2018).

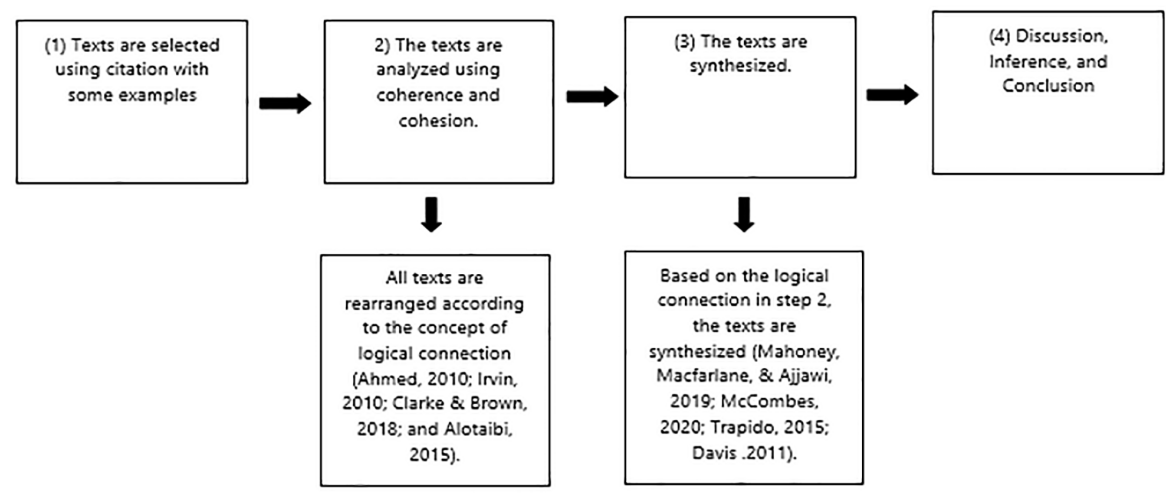

Figure 2. Process of Text Analysis

This study is also a conceptual analysis using some pieces of literature conceptually synthesized -in brief-for making a framework to see the application in academic writing. This study provides examples of analysis based on the references cited, then presented in paragraphs to show the difference between the academic writing that is not synthesized and synthesized. This is based on the concepts of coherence, cohesion, synthesis, novelty as in the framework of this study (see Figure 2).

\subsection{Discussion}

In this section, coherence and cohesion are discussed together because these two terms are interrelated in the application of writing. Figure 2 shows the difference between the text which is synthesized: neither coherent nor cohesive.

\section{Coherence and cohesion}

Coherence is the interrelated ideas that are connected using cohesive devices (Irvin, 2010), and linguistic devices such as register and cohesion are used to make all the ideas interrelated (Ahmed, 2010). In that case, the text can be analyzed using these concepts of coherence and cohesion. In Figure 2, Text A shows that all sentences are discrete. They are not evaluated nor are synthesized. Therefore, this text is not academically well written. The readers will find it difficult to map the novelty of the new idea created from the references that have been cited.

Unlike Text A, Text B is synthesized by the general statement on the top as the topic sentence. This general statement indicates that the author understands what he has cited, and then he creates his own idea. More importantly, Text B shows the interrelated ideas which are connected with cohesiveness: linguistic devices. These devices are such as first, another, like, and also. They are important linguistic devices (cohesive) for making the ideas coherent. 


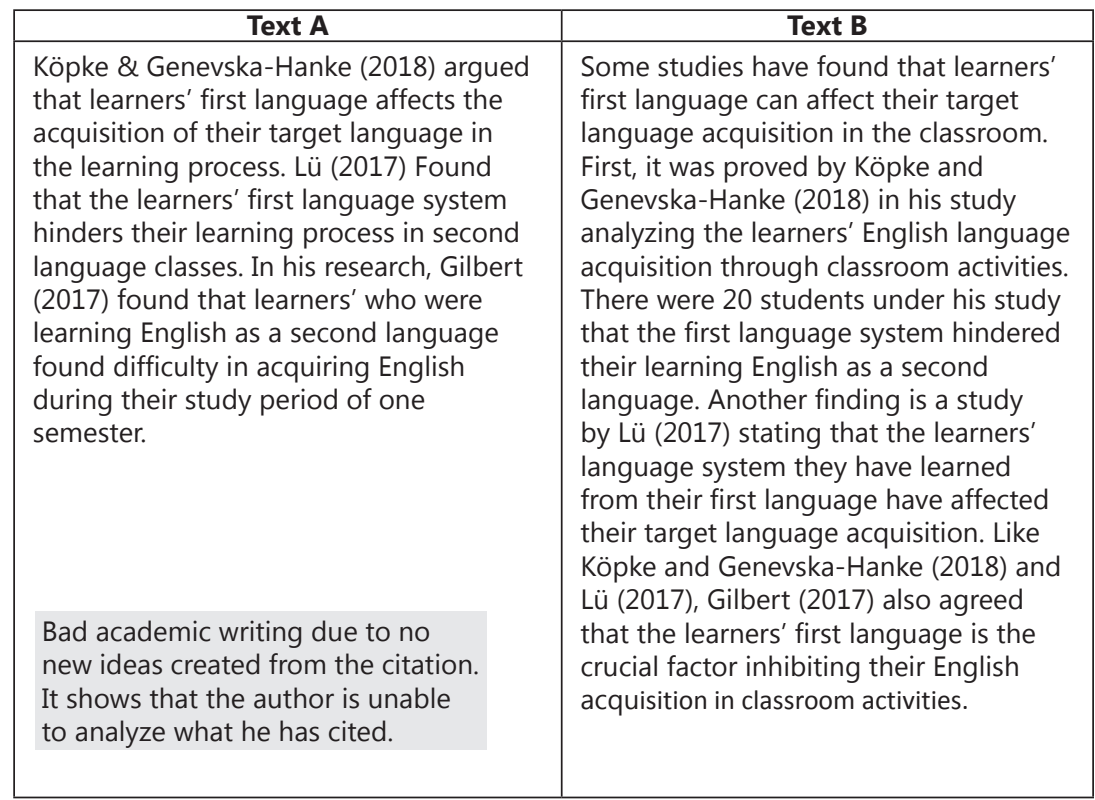

Looking at the citation in text $A$, the author can be judged that $s /$ he is unable to get the idea from what $\mathrm{s} / \mathrm{he}$ has already cited. This is due to the lack of knowledge and skill-based on the concept of coherence and cohesion (Ahmed, 2010; Irvin, 2010; and Alotaibi, 2015). Besides being lacking in coherence and cohesion concept, the author also lacks the knowledge and skill to synthesize the text: ideas from the references $\mathrm{s} /$ he has cited. Therefore, there is now a new idea (novelty) in this kind of academic writing (Davis, 2011; McCombes, 2020; Trapido, 2015; Shibayama \& Wang, 2020). Unlike text $B$, it is already synthesized, and the ideas in the whole text are already interrelated.

\section{Synthesis process}

Synthesizing can be done by making a list of all the ideas from different sources. Table 1 shows the list of ideas from different sources. The author can describe this list using his own words based on the list in Table 1.

Table 1. List of ideas from different sources (A, B, and C)

\begin{tabular}{|c|c|c|c|c|c|}
\hline SOURCE & AIMS & METHODS & POPULATIONS & CONCLUSIONS & EVALUATION \\
\hline 1(A, 2019) & $\begin{array}{c}\text { To examine } \\
\text { the factors } \\
\text { learning } \\
\text { motivation }\end{array}$ & $\begin{array}{c}\text { Quantitative: } \\
\text { Descriptive } \\
\text { Statistics, } \\
\text { SPSS }\end{array}$ & 70 students & $\begin{array}{c}\text { School facilities } \\
\text { very dominants } \\
\text { affecting } \\
\text { motivation }\end{array}$ & $\begin{array}{c}\text { School facilities } \\
\text { should be paid } \\
\text { attention in order to } \\
\text { increase students } \\
\text { motivation }\end{array}$ \\
\hline $2(B, 2010)$ & $\begin{array}{c}\text { To increase } \\
\text { learner's } \\
\text { motivation }\end{array}$ & $\begin{array}{c}\text { Qualitative: } \\
\text { Interview }\end{array}$ & $\begin{array}{c}130 \\
\text { respondents } \\
\text { SHS students }\end{array}$ & $\begin{array}{c}\text { Teachers } \\
\text { expertise } \\
\text { affecting } \\
\text { motivation } \\
\text { dominantly }\end{array}$ & $\begin{array}{c}\text { Teachers' skills helps } \\
\text { learners to learn in } \\
\text { the classroom rather } \\
\text { than other factors }\end{array}$ \\
\hline $3(C, 2011)$ & $\begin{array}{c}\text { Find factors } \\
\text { affecting } \\
\text { learners' } \\
\text { motivation }\end{array}$ & $\begin{array}{c}\text { Quantitative: } \\
\text { Descriptive } \\
\text { Statistics } \\
\text { SPSS }\end{array}$ & 25 respondents & $\begin{array}{c}\text { Home condition } \\
\text { is the most } \\
\text { important to } \\
\text { increase } \\
\text { motivation }\end{array}$ & $\begin{array}{c}\text { In order to increase } \\
\text { students motivation, a } \\
\text { home condition } \\
\text { should be paid } \\
\text { attention }\end{array}$ \\
\hline
\end{tabular}


Table 2. A Summary of the whole ideas from different sources (A, B, and C)

\begin{tabular}{|c|c|c|c|}
\hline Wider Theme & Source 1 & Source 2 & Source 3 \\
\hline $\begin{array}{l}\text { Factors } \\
\text { affecting the } \\
\text { students' } \\
\text { motivation }\end{array}$ & $\begin{array}{l}\text { Facilities at schools } \\
\text { have an important } \\
\text { role in increasing } \\
\text { students/ motivation } \\
\text { to learn. It can be } \\
\text { proved by } 70 \\
\text { students analyzed in } \\
\text { research (A, 2009) }\end{array}$ & $\begin{array}{l}\text { Teachers' skill or } \\
\text { expertise is essential } \\
\text { for making the } \\
\text { students motivated. } \\
B \text { (2010) found that } \\
\text { the students with the } \\
\text { high score he } \\
\text { studied were } \\
\text { motivated in their } \\
\text { learning due to their } \\
\text { teachers who have } \\
\text { good expertise in } \\
\text { teaching. }\end{array}$ & $\begin{array}{l}\text { The students are highly } \\
\text { motivated in their } \\
\text { learning due to their } \\
\text { good home conditions. } \\
C(2011) \text {, in his finding, } \\
\text { proved that the } \\
\text { students with their } \\
\text { home condition got } \\
\text { higher scores in their } \\
\text { studies because of their } \\
\text { good home conditions. }\end{array}$ \\
\hline
\end{tabular}

Based on the list in Table 1 and Table 2, the author can describe it using his own words. According to Davis (2015), this is the best way to find differences or similarities among the arguments and ideas already read and cited. However, he has to edit and revise to get the refined idea. Editing and revising based on the concept of coherence and cohesiveness (Ahmaed, 2010; Alotaibi, 2015; Moore, 2018; Mahoney et al., 2019; Djuwari, 2012; McComber, 2020, and Trapedo, 2015) suggest that the synthesis can be done by editing and reviewing based on the ideas and then using cohesiveness concepts. The process is as to the following.

\section{Text 1 before being edited}

Facilities at schools, teachers' skills, and home conditions are the three factors that can increase students' motivation. Facilities at the schools have an important role in the effort of increasing students' motivation to learn. It can be proved by 70 students analyzed in research statistically Edwards-Jones et al. (2018).The students with complete facilities proved to make them highly motivated. Teachers' skill or expertise is essential for making the students motivated. (Brown\& Rodriguez, 2017) found that the students with high scores he interviewed were motivated in their learning due to their qualified teachers. The students are profoundly driven in their learning due to their good home conditions. Christopher (2012), in his finding, proved that the students with their good home condition got higher scores in their studies.

\section{Text 1 after being edited}

Facilities at schools, teachers' skills, and home conditions are the three factors that can increase students' motivation. First, a study conducted by EdwardsJones et al. (2018) by interviewing 119 staff members in his analysis- showed that school facilities have an important role in increasing students' motivation to learn. Students with complete facilities at schools tend to get high scores because they feel well-assisted. Another factor that can affect students' motivation is the teachers' expertise. This is proved by the evidence (Brown\& Rodriguez, 2017). Based on his study, with 70 students analyzed, it was found that teachers' skill or expertise is essential for making the students motivated. Not only school facilities and the teachers' expertise, according to Christopher(2012), the home condition is the most important factor for them to learn.

Text 2 shows the result of editing and reviewing. In this process, the authors should use the concept as suggested by Davies (2011).From the synthesized text above, the framework can be drawn as in Figure 4. 


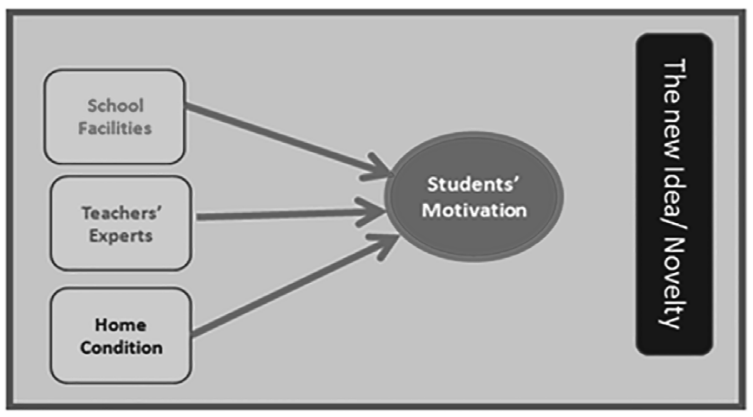

Figure 4. Framework Based on the Citation and Synthesis

In a nutshell, synthesis can also be done by making another new thesis from thesis and antithesis. This can be done as follows:

\section{Synthesis 1, Antithesis, and Synthesis 2 (Modified by the Author)}

\begin{tabular}{|l|l|}
\hline Synthesis 1 & $\begin{array}{l}\text { Learning English as a second language is similar to learning } \\
\text { English as a foreign language provided that the classroom } \\
\text { process is made meaningful (Author A, 2016) }\end{array}$ \\
\hline Antithesis 2 & $\begin{array}{l}\text { Learning any language- whether English as a foreign language } \\
\text { (EFL) or English as a second language (ESL) - does not always } \\
\text { acquire the target language exactly the same as the native } \\
\text { speakers' acquisition. When looking at the concept of world } \\
\text { Englishes, learning English tends to be learned communicatively. } \\
\text { Many nations speak English with their identities, thus, } \\
\text { characterizes their typical accents and varieties. In that case, } \\
\text { there is no difference between learning English as an EFL and as } \\
\text { an ESL (Author B, 2017). }\end{array}$ \\
\hline Synthesis 2 & $\begin{array}{l}\text { Learning English for the learners is a more complex problem, but } \\
\text { when the teachers understand the conditions of their learners, } \\
\text { whether they are learners of EFL or as ESL, differences among } \\
\text { the learners' background can be taken into account when the } \\
\text { classroom process begins (New Idea). }\end{array}$ \\
\hline
\end{tabular}

The original idea (synthesis 1) in Author A (2016) results from synthesizing based on the previous references. Then, it is combined with Antithesis 2, as argued by Author B (2017). Finally, it can be synthesized for the second one, and that is Synthesis 2 (New Idea). When quoting from several references, the author should incorporate ideas

\subsection{Conclusion}

In this descriptive and qualitative analysis, ideas are based on the references cited. Then they are evaluated based on the differences and similarities. From these two, new ideas are created. Therefore, the authors' ideas as syntheses. In order to create novelty, any author of research articles should apply the concept of coherence and cohesion. These two concepts are important for making ideas interrelated. By synthesizing all the ideas that have been cited, any author can write his idea, and that is the novelty. The framework of any study is built from several novelties derived from several sources that have been synthesized.

This descriptive and conceptual study is based on the concepts of synthesis, coherence, cohesion, and novelty. It is also library research based on written references and previous studies. However, it has some limitations. Future studies would be more helpful to further explore using some written data from different sources with different perspectives, such as texts from dissertations or some research journal articles from different levels of status accreditations. 


\section{REFERENCES}

Abas, I. H., \&AbdAziz, N. H. (2017). Classification of the L2 writing process and writing strategies. Proceedings of the ICECRS, 1(1). https://doi.org/10.21070/picecrs.v1i1.505

Ahmad, M., Mahmood, M. A., \& Siddique, A. R. (2019). Organizational skills in academic writing: A study on coherence and cohesion in Pakistani research abstracts. Languages, 4(4), 92. https://doi.org/10.3390/ languages4040092

Ahmed, A. H. (2010). Students' problems with cohesion and coherence in EFL essay writing in Egypt: Different perspectives. Literacy Information and Computer Education Journal (LICEJ), 1(4), 211-221. https://doi. org/10.20533/LICEJ.2040.2589.2010.0030

Akinyode, B. F., \& Khan, T. H. (2018). Step by step approach for qualitative data analysis. International Journal of Built Environment and Sustainability, 5(3). https://doi.org/10.11113/ijbes.v5.n3.267

Alotaibi, H. (2015). The role of lexical cohesion in writing quality. International Journal of Applied Linguistics and English Literature, 4(1), 261-269. http://dx.doi.org/10.7575/aiac.ijalel.v.4n.1p.261

Azizah, U. Arifatul\&Budiman, Asep (2017). Challenges in Writing Academic Papers for International Publication among Indonesian Graduates Students. In JEELS, Volume 4, Number 2, November 2017

Brown, T. M., \& Rodriguez, L. F. (2017). Collaborating with urban youth to address gaps in teacher education. Teacher Education Quarterly, 44(3), 75-92. https://www.jstor.org/stable/90010904

Bacon, E. D., \& Bounty, T. (2020). Utilizing peer feedback by synthesizing a peer-assisted learning center with an English course to develop English grammar and academic writing skills. Rangsit Journal of Educational Studies, 7(1), 34-45. https://rsujournals.rsu.ac.th/index.php/RJES/article/view/1563

Clarke, V., \& Braun, V. (2018). Using thematic analysis in counseling and psychotherapy research: A critical reflection. Counseling and Psychotherapy Research, 18(2), 107-110. https://doi.org/10.1002/capr.12165

Christopher, K. (2012). Extensive mothering: Employed mothers' constructions of the good mother. Gender \& Society, 26(1), 73-96. https://doi.org/10.1177/0891243211427700

Davies, M. (2011). Concept mapping, mind mapping, and argument mapping: what are the differences, and do they matter? Higher education, 62(3), 279-301. https://link.springer.com/ article/10.1007\%2Fs10734-010-9387-6

Djuwari, D. (2012). Arguments by the contributors of research journal publication. IAMURE International Journal of Social Sciences, 2(1), 1-1.

Edwards-Jones, A., Waite, S., \& Passy, R. (2018). Falling into LINE: school strategies for overcoming challenges associated with learning in natural environments (LINE). Education 3-13, 46(1), 49-63. https://doi.org/10.108 0/03004279.2016.1176066

Gilbert, J. (2017). A study of ESL students' perceptions of their digital reading. The reading matrix: an international online journal, 17(2), 179-195. http://mail.readingmatrix.com/files/17-z2d49xa9.pdf

Irvin, L. L. (2010). What Is "Academic" Writing? Writing spaces: Readings on writing, 1, 3-17.

Köpke, B., \& Genevska-Hanke, D. (2018). First language attrition and dominance: Same or different? Frontiers in Psychology, 9, 1963. https://doi.org/10.3389/fpsyg.2018.01963

Knight, S., Shum, S. B., Ryan, P., Sándor, Á. \& Wang, X. (2018). Designing academic writing analytics for civil law student self-assessment. International Journal of Artificial Intelligence in Education, 28(1), 1-28. https://link. springer.com/article/10.1007/s40593-016-0121-0

Lü, C. (2017). The roles of pinyin skill in English-Chinese biliteracy learning: Evidence from Chinese immersion learners. Foreign Language Annals, 50(2), 306-322. https://doi.org/10.1111/flan.12269

Mahoney, P., Macfarlane, S., \& Ajjawi, R. (2019). A qualitative synthesis of video feedback in higher education. Teaching in Higher Education, 24(2), 157-179. https://doi.org/10.1080/13562517.2018.1471457

McCombes, S. (2020) How to Synthesize Written Information from Multiple Sources. https://www. simplypsychology.org/synthesising.html\#step1

Moore, J. D. (2018). What does it mean to synthesize for writing assignments? In Guy Counselling. https:// guycounseling.com/synthesis-writing/

Patriotta, G. (2017). Crafting papers for publication: Novelty and convention in academic writing. https://doi. org/10.1111/joms.12280

Rasmuson, Elmer E. (2020). Library Research Process. https://library.uaf.edu/ls101-research-process

Shibayama, S., \& Wang, J. (2020). Measuring originality in science. Scientometrics, 122(1), 409-427. https://link. springer.com/article/10.1007/s11192-019-03263-0

Trapido, D. (2015). How novelty in knowledge earns recognition: The role of consistent identities. Research Policy, 44(8), 1488-1500. https://doi.org/10.1016/j.respol.2015.05.007

\section{Correspondence:}

DJUWARI DJUWARI

djuwarisehat@gmail.com

https://orcid.org/0000-0003-1717-4448 